\title{
Effect of Fibre Orientation on Mode-I Interlaminar Fracture Toughness of Glass Epoxy Composites
}

\author{
M. R. SHETTY, K. R. VIJAY KUMAR, S. SUDHIR, \\ P. RAGHU AND A. D. MADHURANATH \\ Department of Polymer Science and Technology \\ SJCE \\ Mysore, India \\ R. M. V. G. K. RAO' \\ FRP Pilot Plant Unit \\ National Aerospace Laboratories \\ Bangalore, 560017 India
}

\begin{abstract}
The mode-l interlaminar fracture toughness (IFT) property of room temperature (RT) cured glass-epoxy (LY556/HY951) composites was studied using a double cantilever beam (DCB) test specimen with unidirectional fibre orientations of $0^{\circ},+45^{\circ}-45^{\circ}$. $+60^{\circ} /-60^{\circ}$ and $90^{\circ}$ in the neighborhood of the crack zone. Three IFT data reduction techniques, viz: (1) Modified Beam Theory (MBT). (2) Compliance Calibration Theory (CC) and (3) Modified Compliance Calibration Theory (MCC) were verified for the DCB data generated for $0^{\circ}$ fibre oriented specimens. The fracture toughness property estimates were noted to be approximately the same for all three techniques. Only the MBT reduction procedure (as per ASTM) was used for other orientations. It was observed that the IFT increased as the fibre orientation was changed from $0^{\circ}$ to $90^{\circ}$ with reference to the direction of crack propagation.
\end{abstract}

KEY WORDS: Mode-I interlaminar fracture toughness. double cantilever beam. delamination. fibre orientation.

\section{INTRODUCTION}

GUSCEPTiBility to delamination is one of the inherent weaknesses of even ad$\$$ vanced laminated composite structures [1]. This often precipitates component

'Author to whom correspondence should be addressed.

Joumal of REINFORCED PLASTICS AND COMposites. Vol. 16. No. ??/1999 


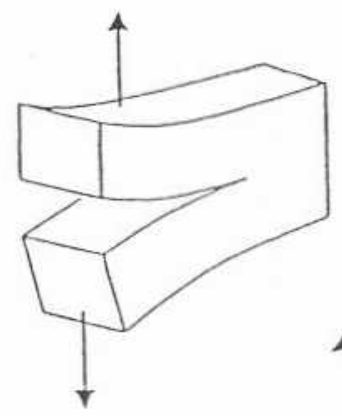

Mode $1\left(\mathrm{G}_{1}\right)$

(Opening)

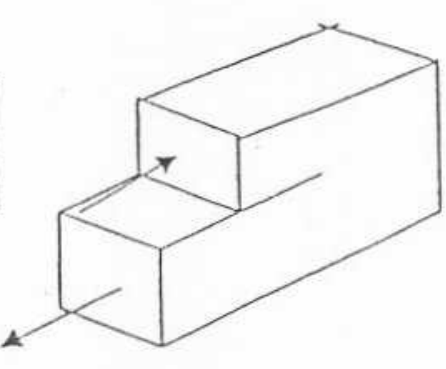

Mode II $\left(\mathrm{G}_{\| 1}\right)$

(Shcaring)

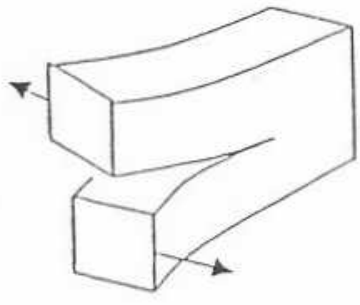

Mode $111\left(\mathrm{G}_{\mathrm{II}}\right)$

(Tearing)

Figure 1. Modes of Interlaminar Fracture Toughness.

repair or replacement, inhibiting fleet readiness in case of aircraft and results in increased lifecycle costs. Delamination growth in composites can occur too rapidly over a fairly small range of load, and hence the interlaminar fracture toughness (IET), $G$, needs ta.beconsidered_indamagetolerance analysis [2-4].

The IFT property of a composite is a measure of its ability to resist interlaminar propagation of a "delamination or crack like" defect, which incidentally constitutes a vital energy absorption process. Fibre surface treatment, matrix toughness/brittleness, process conditions, fibre volume fraction and environmental variables influence this IFT property.

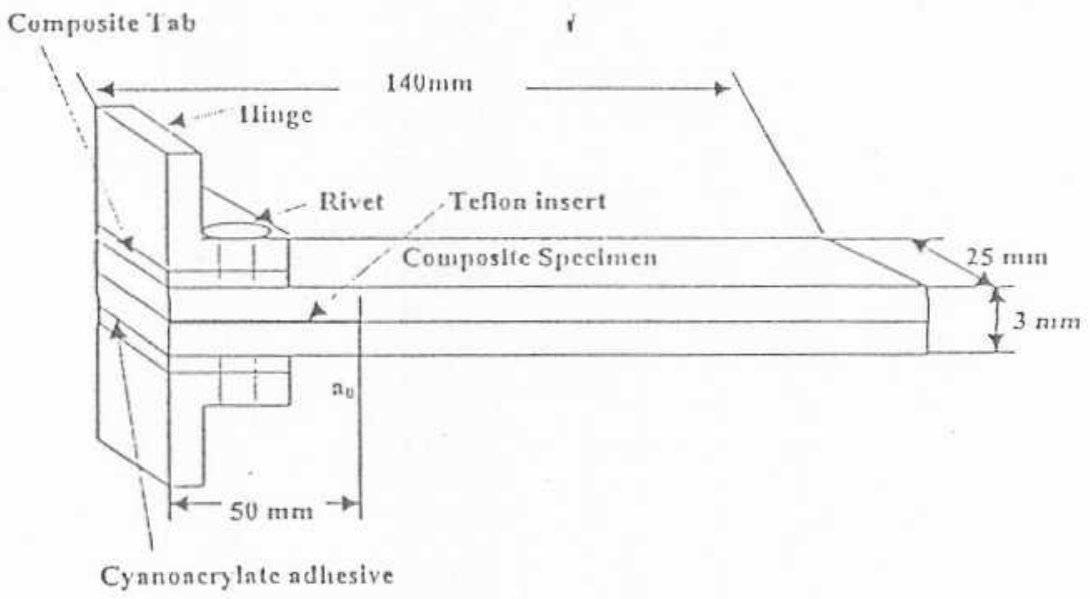

Figure 2. Schematic diagram of the DCB specimen. 
IFT measurements are made by three basic modes, as shown in Figure 1, in terms of the strain energy release rate $\left(G_{l}\right.$ or $G_{l l}$ or $\left.G_{I I}\right)$, i.e., the energy dissipated per unit area of delamination growth $[5,6]$.

Mode-I interlaminar fracture toughness $\left(G_{l_{c}}\right)$ values are usually measured by using a double cantilever beam (DCB) specimen (Figure 2) [7-10].

Studies on fibre orientation effects on IFT property of laminated composites are of practical significance, since in aircraft structures, different fibre orientations are used by designers, as for instance $0^{\circ}$ orientation used in spar-caps and multi-angular constructions in wing skins.

As literature does not provide data on comparing the effects of fibre orientation on the $G_{l c}$, studies were carried out and reported for DCB specimens, incorporating unidirectional glass epoxy layups with crack propagation zone/plane having orientations of $0^{\circ},+45^{\circ} \%-45^{\circ},+60^{\circ} \%-60^{\circ}$ and $90^{\circ}$.

\section{THEORETICAL CONSIDERATIONS}

Three initiation values of $G_{l c}$ have been defined [11]. These include $G_{l c}$ values determined using the load and deflection measured (1) at the point of deviation from linearity in the load displacement curve (NL), (2) at the onset of delamination visually obseryed on the edge (VIS) measured with a magnifying lens and (3) at the point where the compliance has increased by $5 \%$ or wliere the load has reached a maximum value $(5 \% / \max )$. The $\mathrm{NL}$ or non-linearity $G_{I c}$ initiation value, which is typically the lowest of the three, was recommended for evolving the delamination failure criteria useful in the analysis of damage tolerance of laminated composite structures. In round robin testing of AS4/PEEK thermoplastic matrix composites, NL- $G_{I c}$ values were $20 \%$ lower than VIS and $5 \% / \max$ values [10]. Physical evidence indicated that the initiation values corresponding to the onset of non-linearity (NL) in the load displacement plot corresponds to the physical onset of delamination at the tip of the insert found in the mid-plane of the specimen width [12].

\section{EXPERIMENTAL}

\section{Test Laminate Preparation}

Room temperature cured E-glass/epoxy (LY556/HY951) was the composite system used in these studies. As shown in Figure 3, 14 layers of bi-directional (BID) glass fabric were used to make up the outer composite substrate of the laminate and 4 layers of unidirectional glass tape made up the inner middle layers (variable fibre orientation zone) of the laminate of size $300 \mathrm{~mm} \times 200 \mathrm{~mm}$. The total 


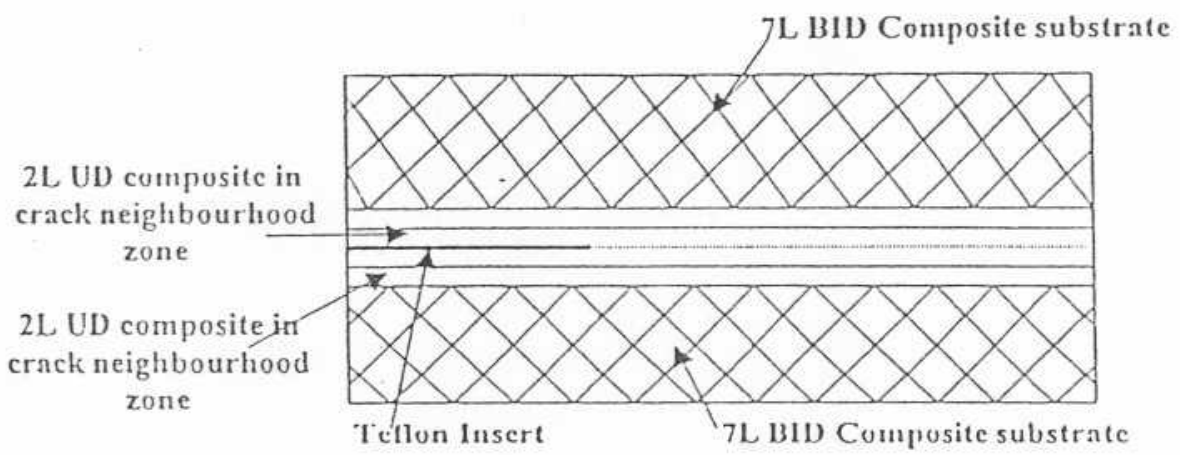

Figure 3. Schematic diagram of the test laminate cross section.

thickness of the laminate was measured at $3 \mathrm{~mm}$ using a compression press and accurate spacers. A Teflon insert of thickness $3 \mu \mathrm{m}$, and length $50 \mathrm{~mm}$, was used in the laminate as an artificial delaminator or crack initiator. Figure 3 shows the schematic cross section of the test laminate out of which the DCB test specimens of size $140 \mathrm{~mm} \times 25 \mathrm{~mm}$ (Figure 2) were sliced off.

\section{DCB-Test Specimen Preparation}

The dimensional features of the DCB specimen are shown in Figure 2. Piano hinges were riveted to composite tabs and these tabs were glued using a cyanoacrylate adhesive to the specimen at the Teflon insert end of the specimen.

The edge of each specimen just ahead of the insert was coated with a thin layer of water-based typewriter correction fluid to facilitate visual detection of delamination onset. The first $5 \mathrm{~mm}$ from the insert, were marked with thin vertical lines every $1 \mathrm{~mm}$ apart. The remaining part of the specimen was marked $5 \mathrm{~mm}$ apart. The delamination length was found as the sum of the distances from the loading line to the end of the insert plus the increment of the growth determined by following the tick marks.

Photographs of the DCB specimens are shown in Figures $4 \mathrm{a}$ and $4 \mathrm{~b}$.

\section{DCB Test Procedure}

A Universal Testing Machine (Instron 6025) was used to conduct the DCB tests. The hinges on the specimen were mounted in the grips of the loading machine, making sure that the specimen is aligned and centered. The crosshead speed is set at $0.5 \mathrm{~mm} / \mathrm{min}$ to ensure a steady crack propagation monitored using a magnifying lens,

The specimen was loaded continuously in displacement control mode. The load 


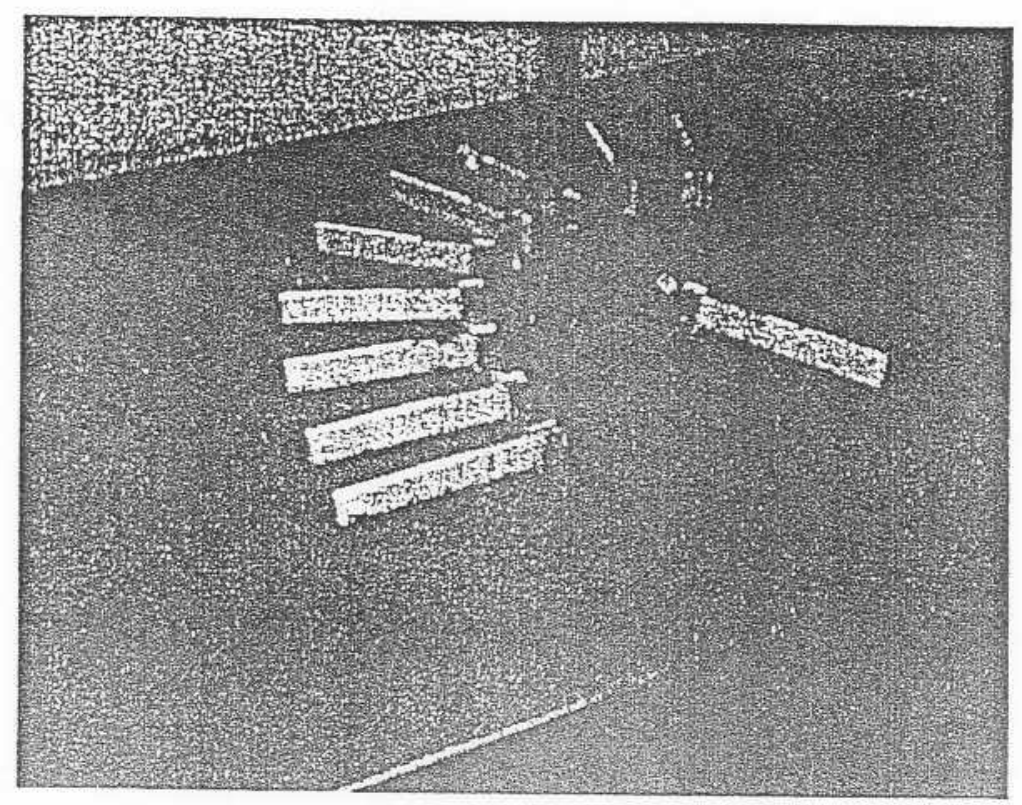

Figure 4a. Photograph of DCB test specimens.

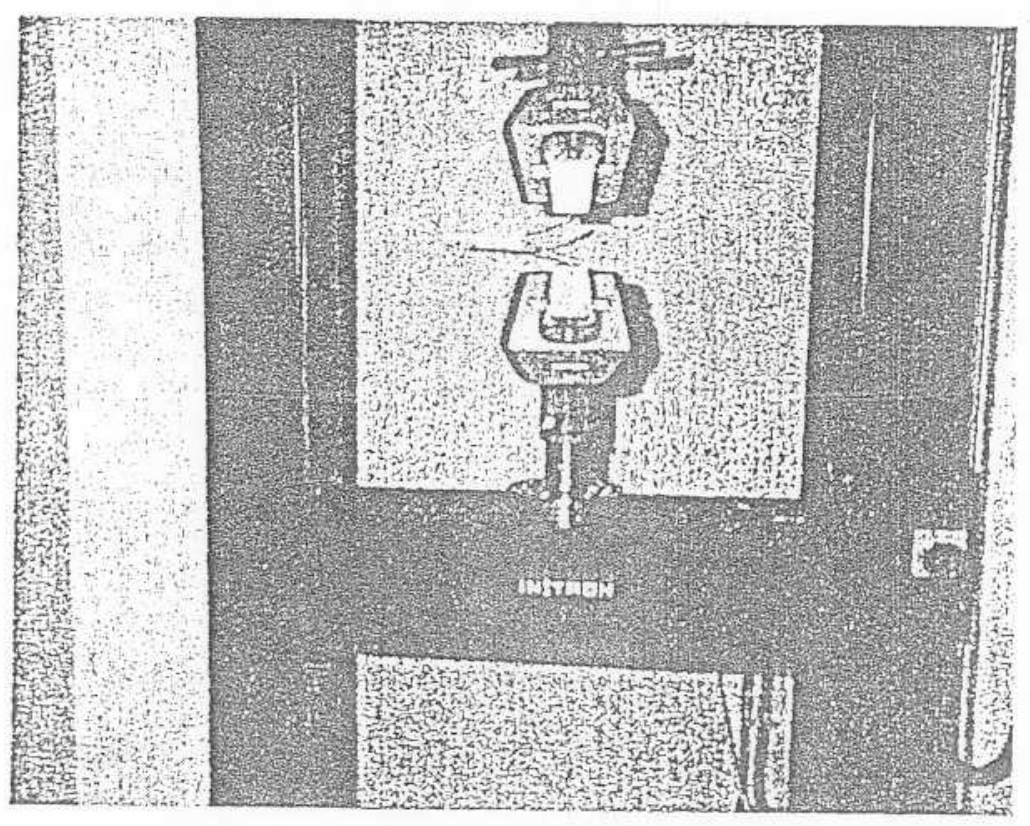

Figure $4 b$. Photograph of DCB test in progress. 
$(P)$ versus opening displacement $(\delta)$ was recorded on an $X-Y$ chart recorder. The delamination front was observed visually from the end of the Teflon insert. When the delamination grows from the end of the Teflon insert, this point was marked as $a_{0}$ on the plot of $P$ vs $\delta$. Therefore $a_{0}$ will be the initial delamination length, i.e., the distance from the load line to the end of the Teflon insert. As the delamination length grew from the end of the Teflon insert, due to the load applied, the delamination front positions were marked on the $P$ vs $\delta$ trace, in the sequence $a_{1}$, $a_{2}, a_{3} \ldots a_{n}$. For the first $5 \mathrm{~mm}$ of crack growth, the instantaneous delamination front positions were recorded at $1 \mathrm{~mm}$ intervals. After the first $5 \mathrm{~mm}$ of delamination growth from the Teflon insert border, every $5 \mathrm{~mm}$ of delamination growth was indicated on the $X-Y$ plot. The values of $P$ and $\delta$ are used in the evaluation of IFT.

The visually observed point of delamination onset is marked on the $P$ vs $\delta$ curve as $a_{0}$. This point would give the load and displacement required to calculate the visually observed $G_{l c}$ initiation value or VIS. The point where non-linearity starts on the $P$ vs $\delta$ curve is also marked. This point was considered to calculate the non-linearity $G_{l c}$ initiation value or NL.

Another type of $G_{l c}$ initiation value is the $5 \%$ offset/maximum initiation value
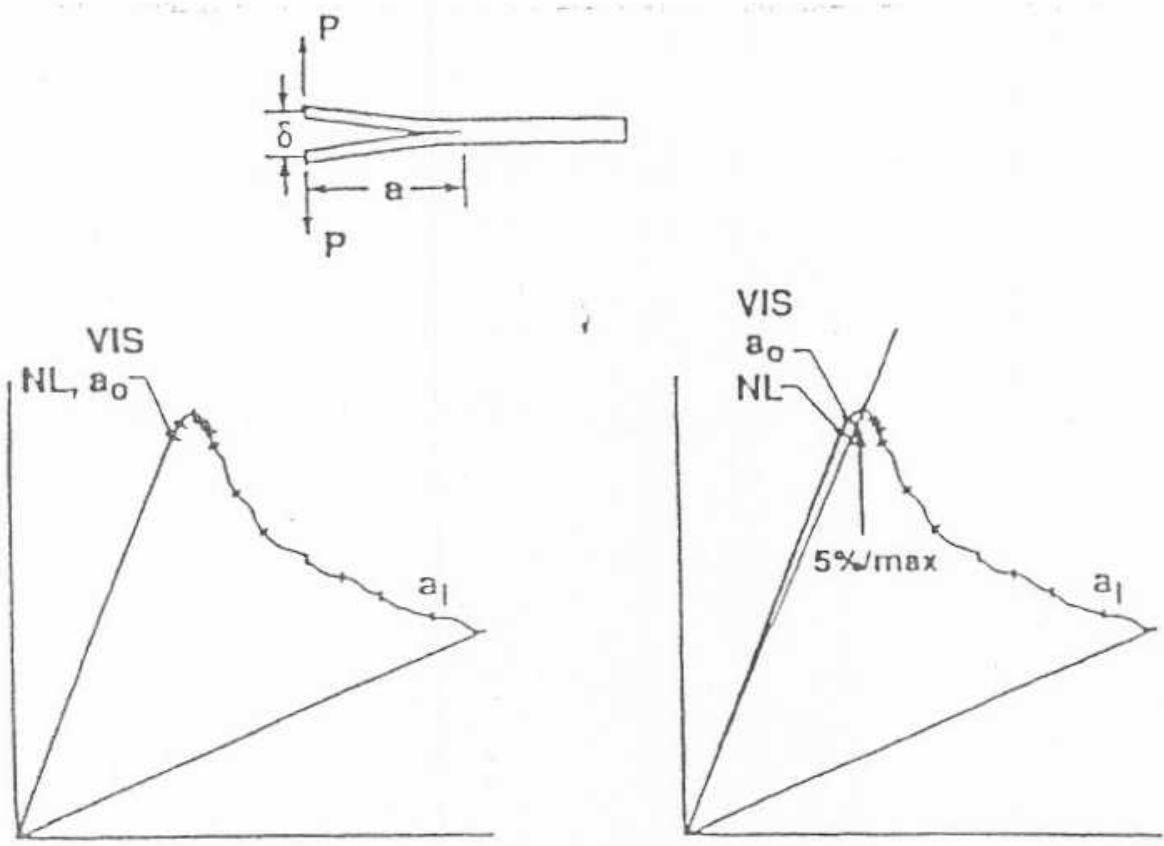

Figure 5. A common load displacomont trace from a DCB tost. 
or $5 \% / m a x$. In this case, the initiation value is calculated by determining the interection of the load-deflection curve, once it has become nonlincar, with a line drawn from the origin and offset by a $5 \%$ increase in compliance from the original linear region of the load-displacement curve (Figure 5). In case the intersection occurs after the maximum load point, the maximum load value should be used to calculate this initiation value.

The data obtained from the DCB test is used to calculate the $G_{l c}$, using three data reduction techniques as follows:

1. Modified Beam Theory (MBT) method [13]: A least square of the cube root of compliance, $C^{1 / 3}$, as a function of the delamination length, $a$, is generated. The compliance $(\delta / P)$ is the ratio of the load point displacement to the applied load. The intercept of this line on the $x$-axis is recorded as $\Delta$. The $G_{l c}$ is calculated using the following expression:

$$
G_{t c}=\frac{3 P \delta}{2 b(a+|\Delta|)}
$$

where $P$ is the load in N, $\delta$ is the load point displacement, $b$ is the width of the specimen, $a$ is the delamination length, and $\Delta$ is the intercept of the plot of $C^{1 / 3} \mathrm{vs}$ $a$ on the $a$-axis.

2. Compliance Calibration (CC) method [14]: A least squares plot of $\log \left(\delta_{i} / P_{i}\right)$ versus $\log a_{i}$ is generated using the visually observed delamination onset values and all the propagation values. The slope of this line is recorded as $n$. The $G_{l c}$ values are obtained using the following expression:

$$
G_{l c}=\frac{n P \delta}{2 b a}
$$

3. Modified Compliance Calibration (MCC) method [15]: A least squares plot of $a / h$ as a function of the cube root of the compliance, $C^{1 / 3}$, was generated using the visually observed delamination onset values and all the propagation values. The slope of this line is $A_{1}$.

The following expression was used to calculate $G_{I c}$ :

$$
G_{l c}=\frac{3 P^{2} C^{2 / 3}}{2 A_{1} b h^{2}}
$$

where $h$ is the thickness of the specimen.

The DCB test procedure used during these studies was a lengthy, steady and rigorous procedure. The values presented herein were ohtained for ene specimen in the case of each fibre orientation. 
Table 1. $\mathrm{G}_{\mathrm{l}}$ initiation and propagation values for room temperature cured $0^{\circ}$ orientation.

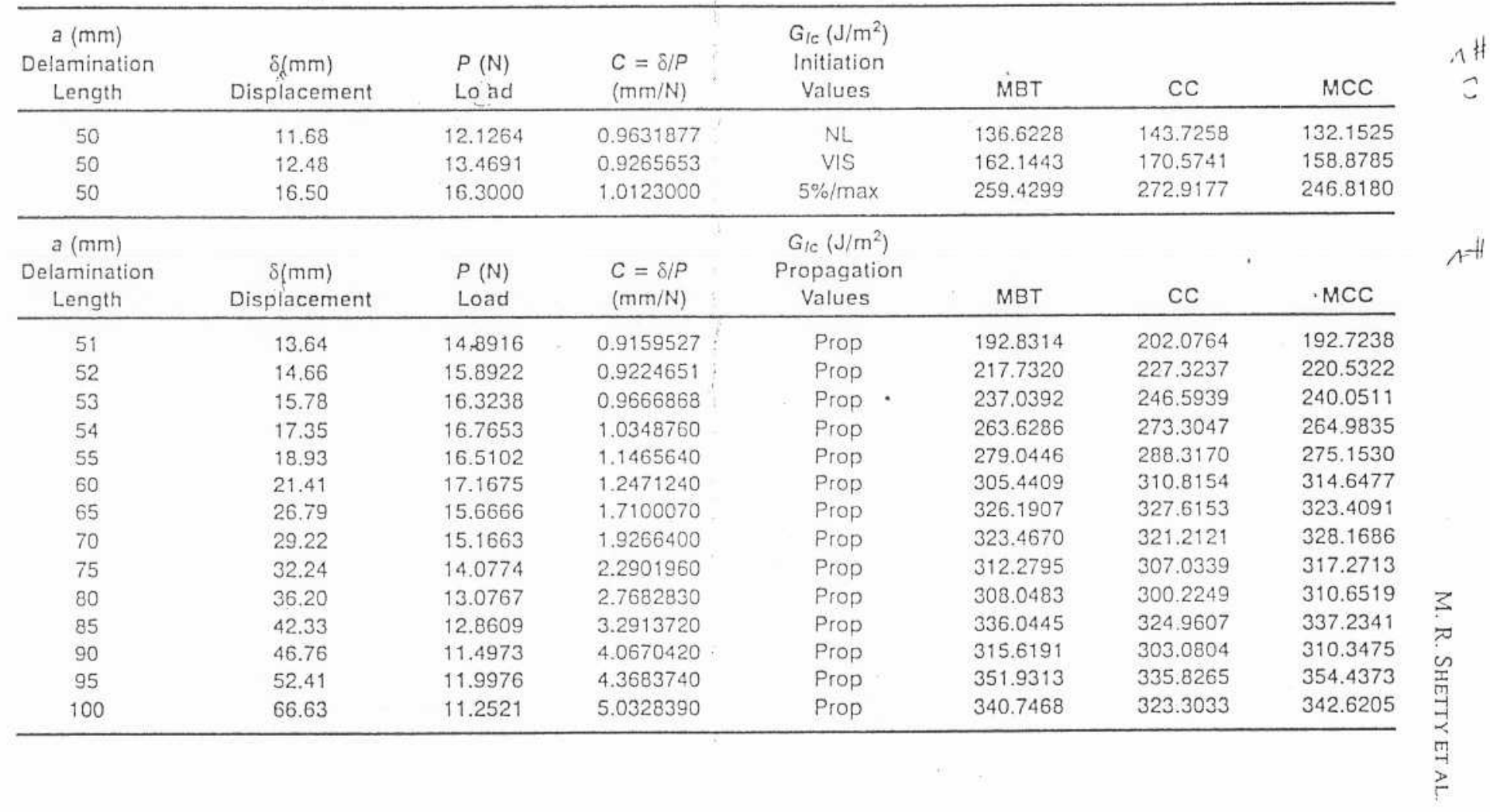


Table 2. $\mathrm{G}_{\mathrm{lc}}$ propagation values of room temperature cured glass epoxy specimens for different orientations.

\begin{tabular}{ccccc}
\hline \multirow{2}{*}{$\mathbf{c}$} & \multicolumn{4}{c}{$\mathrm{G}_{\mathrm{lc}}\left(\mathrm{J} / \mathrm{m}^{2}\right)$} \\
\cline { 2 - 5 }$(\mathrm{mm})$ & $0^{\circ}$ & $+45^{\circ} /+45^{\circ} /-45^{\circ}-45^{\circ}$ & $+60^{\circ} /+60^{\circ} /-60^{\circ} /-60^{\circ}$ & $90^{\circ}$ \\
\hline 51 & 192.8314 & 278.7449 & 277.1419 & 436.0587 \\
52 & 217.7320 & 303.0014 & 307.9624 & 479.5282 \\
53 & 237.0392 & 292.1965 & 335.1141 & 556.1461 \\
54 & 263.6286 & 300.0288 & 342.4193 & 633.4319 \\
55 & 279.0446 & 302.3245 & 353.2673 & 678.9705 \\
60 & 305.4409 & 377.0520 & 453.4111 & 845.5216 \\
65 & 326.1907 & 451.3348 & 530.0248 & 876.0215 \\
70 & 323.4670 & 503.1511 & 538.9803 & 787.2975 \\
75 & 312.2795 & 573.0416 & 569.5624 & 901.1874 \\
80 & 308.0483 & 612.6463 & 591.4561 & 1002.7670 \\
85 & 336.0445 & 657.8785 & 577.4237 & 1079.9770 \\
90 & 315.6191 & 681.1161 & 617.3491 & 1104.8010 \\
95 & 351.9313 & 732.9820 & 668.6404 & 1122.8340 \\
100 & 340.7468 & 820.2808 & 774.3384 & 1280.2750 \\
\hline
\end{tabular}

\section{RESULTS AND ANALYSIS}

Table 1 shows the experimental values of $P, \delta$ and $a$, for the room temperature $0^{\circ}$ fibre oriented specimen. The $P$ vs $\delta$ curve is plotted as shown in Figure 6 , to identify the $G_{t c}$ initiation values (NL. VIS and $5 \% /$ max) on lines of schematic Figure 5. Further, these experimental values are plotted using the MBT, CC and MCC data reduction techniques, as shown in Figures 7,8 and 9 . Since the $G_{l c}$ values, as seen from Table 1, were, in general, the lowest for the MBT technique, further analysis is carried out using the MBT values for all orientations and cure techniques.

Figure 10 shows room temperature cured values as a function of delamination length $a$. It can be noted that the $G_{l c}$ values remain constant beyond $a=60 \mathrm{~mm}$.

\section{Effect of Fibre Orientation}

Table 2 and Figure 11 compare the $G_{l c}$ propagation values calculated by MBT method for RT-cured specimens consisting of different fibre orientations in the crack propagation zone. As can be observed, the $G_{l c}$ propagation values for the $0^{\circ}$ orientations are the lowest while those of the $+45 \%-45^{\circ}$ and the $+60 \%-60^{\circ}$ are similar. The $G_{l c}$ propagation values of the $90^{\circ}$ orientation specimen are the highest of all, and are almost twice those of the $0^{\circ}$ orientation specimen.

The effect of post-cure was also studied in case of $0^{\circ}$ orientation which had presented the most conservative effect of the IFT property. A post-cure schedule of $85^{\circ} \mathrm{C}$ for 2 hrs was used to cure the specimen. Figure 12 compares the $G_{I c}$ values of 


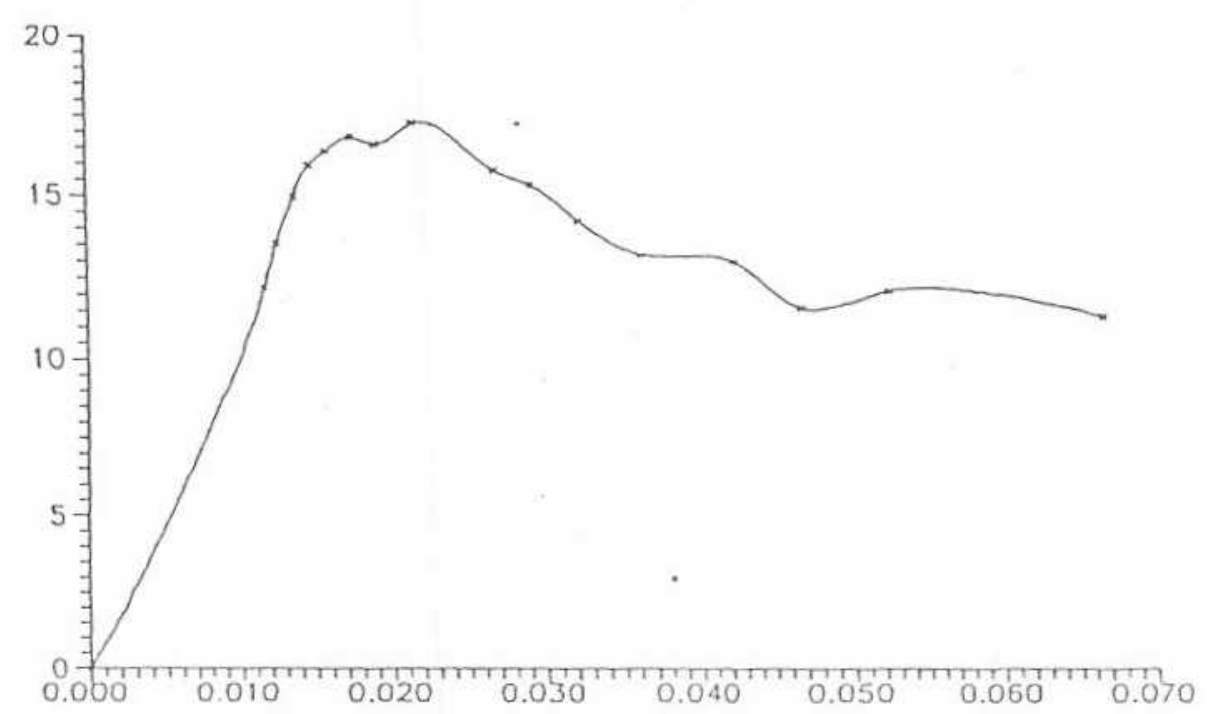

Figure 6. Pvs $\delta$ curve. $x$-axis: load in newtons; $y$-axis: displacement in metres.

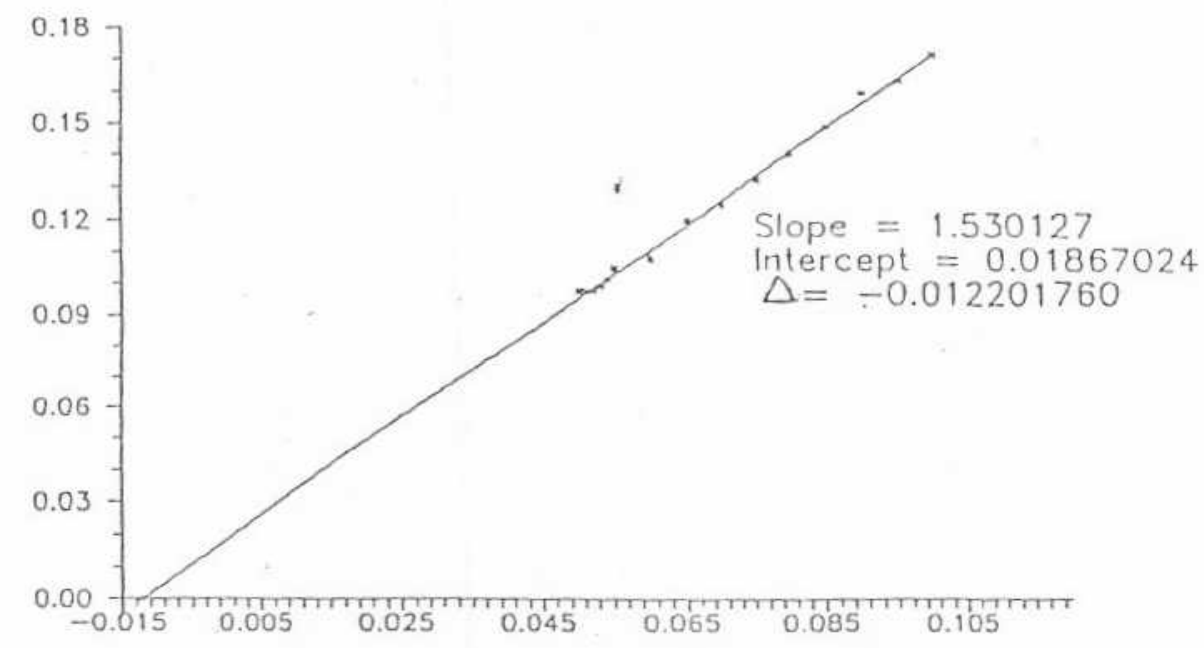

Figure 7. MBT curve. x-axis: delamination length in metres; $y$-axis: (compliance) $)^{1 / 3}$. 


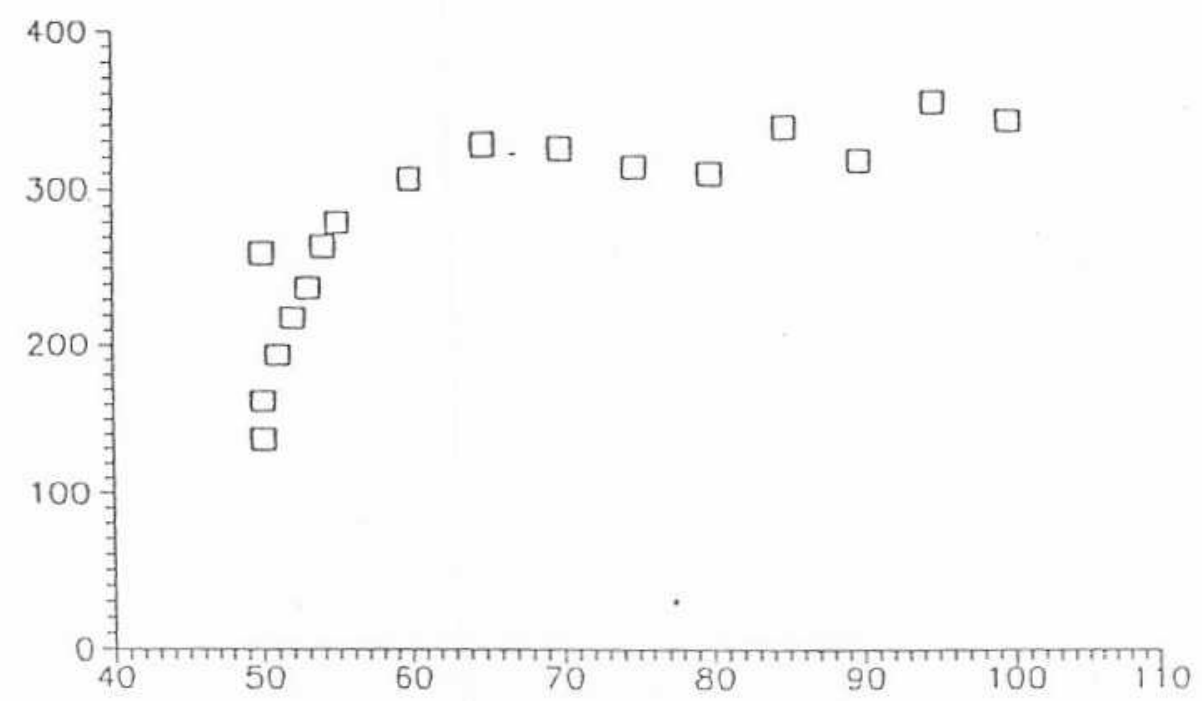

Figure 10. Delamination resistance curve (A-curve) for room temperature cured $0^{\circ}$ oriented $D C B$ specimen. $x$-axis: delamination length in millimetres; $y$-axis: interlaminar fracture toughness in joules/metres.

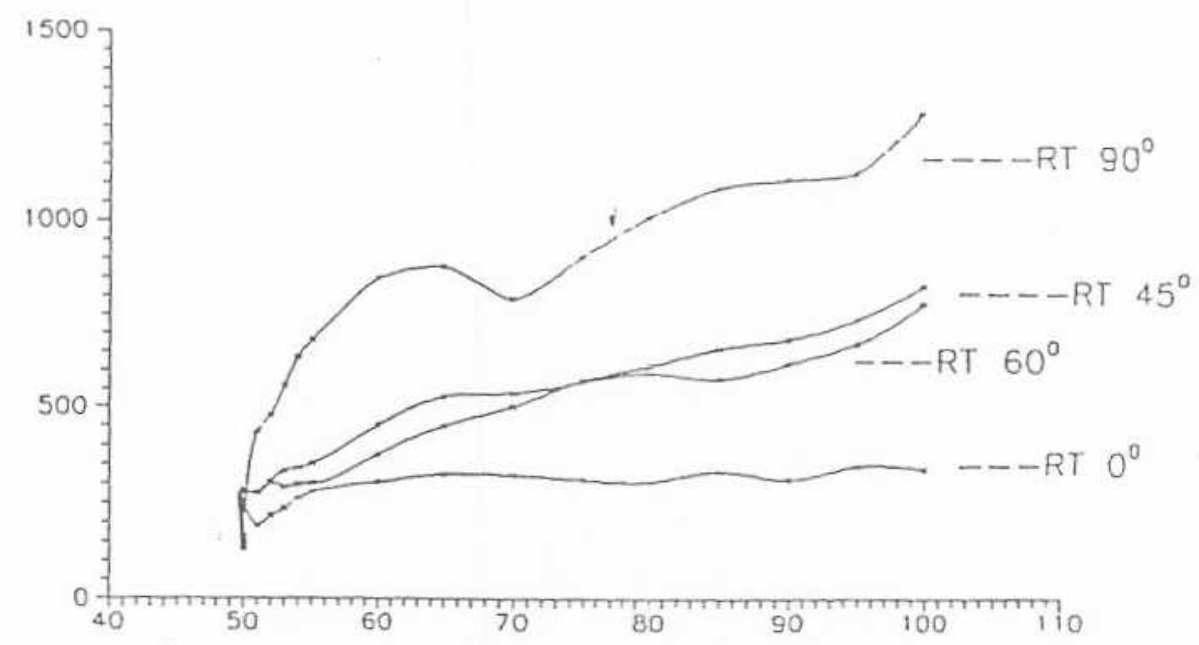

Figure 11. Effect of fibre orientation on $\mathrm{G}_{1 \mathrm{l}}$ propagation values of room temperature cured glass epoxy specimen. $\alpha$-axis; delamination length in millimetres; $y$-axis: interlaminar fracture toughness in joules/(metrès) ${ }^{2}$. 


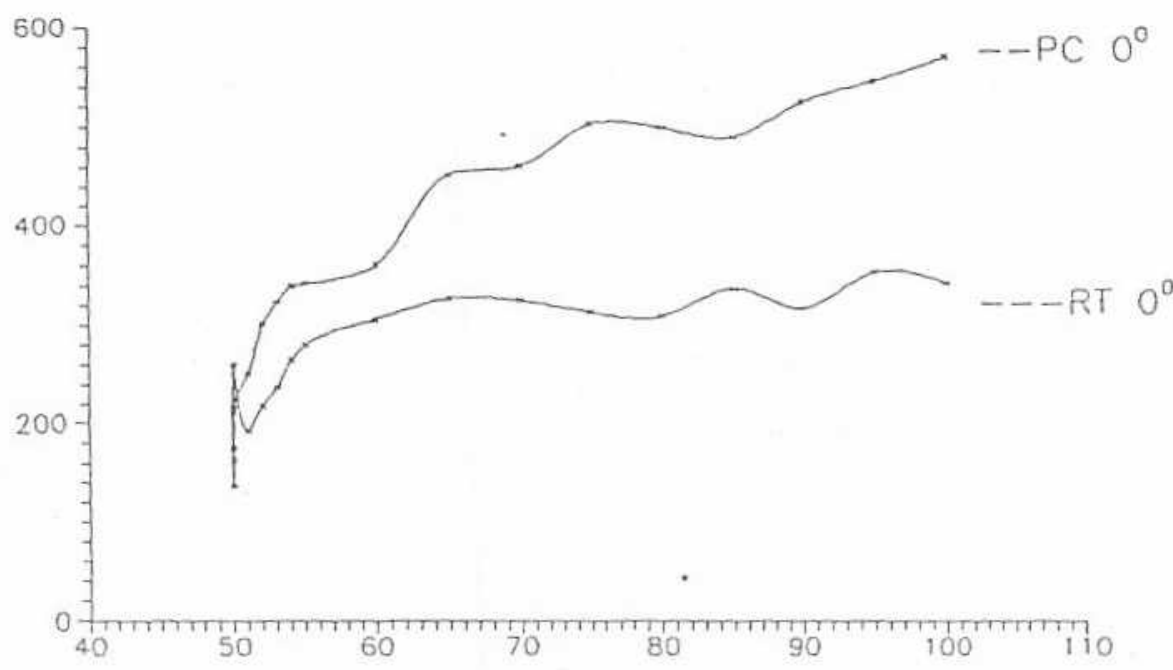

Figure 12. Effect of fibre orientation on $\mathrm{G}_{\mathrm{ic}}$ propagation values of room temperature cured $0^{\circ}$ oriented specimen and step post.cured $0^{\circ}$ oriented specimen. $\mathrm{x}$-axis: delamination length in millimetres; $y$-axis: interlaminar fracture toughness in joules/(metres) ${ }^{2}$.

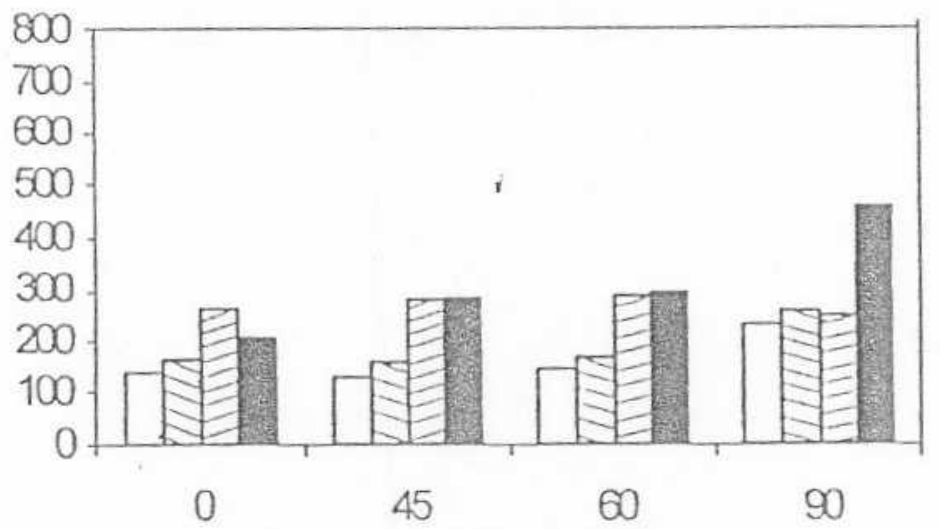

Figure 13. Comparison of $\mathrm{G}_{\mathrm{lc}}$ initiation values and propagation values at $\mathrm{a}=51.5 \mathrm{~mm}$ for room temperature cured specimens of different orientations. $x$-axis: degree olfibre orientation; $y$-axis: interlaminar fracture toughness in joules/(metres) ${ }^{2}$. $\square$ Non-linearity $G_{10}$ initiation values (NL), E Visually observed $\mathrm{G}_{\mathrm{I}_{c}}$ initiation values (VIS), $5 \% / \mathrm{max} \mathrm{G}_{\mathrm{lc}}$ initiation values ( $5 \% / \mathrm{max}$ ), a $\mathrm{G}_{\mathrm{c}}$ initiation values at $\mathrm{a}=51.5 \mathrm{~mm}$. 
the RT cured and the post cured $0^{\circ}$ orientation specimen. It can be seen that the post, cure of the specimen has resulted in higher $G_{l c}$ values.

\section{$\mathrm{G}_{\mathrm{Ic}}$ Initiation Values}

Figure 13 compares the three $G_{/ c}$ initiation values and the $G_{/ c}$ propagation value at the delamination length, $a=51.5 \mathrm{~mm}$ for all the orientations. We see that the NL- $G_{l c}$ initiation values are the lowest among the three $G_{l_{c}}$ initiation values. It is also seen that the effect of fibre orientation on the $G_{l c}$ initiation values is similar to that on the $G_{l c}$ propagation values.

\section{CONCLUSIONS}

When delamination takes place in the $0^{\circ}$ fibre orientation specimen, the crack propagates in a direction parallel to the direction of orientation of the fibre (Figure $14(\mathrm{a})]$, offering very little resistance. It was also observed that step post-cured $0^{\circ}$ orientation specimen exhibited an increase in the $G_{l c}$ values.

It is also seen that the $G_{k c}$ propagation values for the $+45^{\circ} /-45^{\circ}$ and the $+60 \%-60^{\circ}$ specimens are close to each other, apparently due to similarity in resistance offered by the fibres [Figures $14(\mathrm{~b})$ and $14(\mathrm{c})$ ]. It is further observed that the

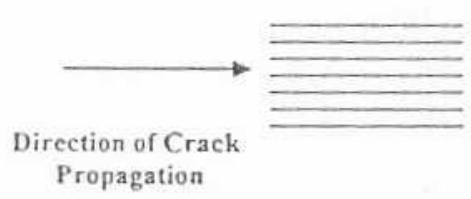

a) $0^{\circ}$ fibre orientation

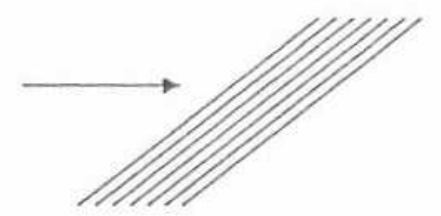

b) $45^{\circ}$ fibre orientation

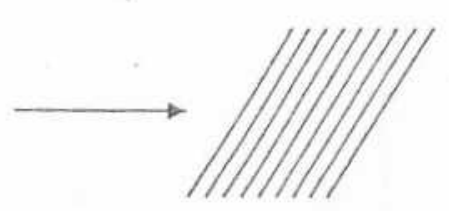

c) $60^{\circ}$ fibre orientation

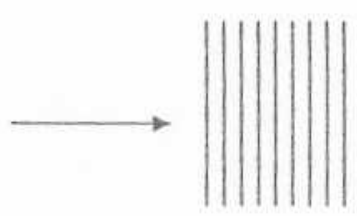

d) $90^{\circ}$ fibre orientation

Figure 14. Schematic representation of crack propagation in composites for different fibre orientations. 
$90^{\circ}$ orientation specimen exhibits the highest fracture resistance, indicating that fibre reinforced composites offer high fracture resistance and durability when their fibres are oriented transverse to the crack propagation line [Figure 14(d)].

Though the $0^{\circ}$ specimen offers the least resistance to crack propagation, this property can form a very realistic comparative estimate of the matrix toughness capability.

\section{REFERENCES}

1. O'Brien. T.K. “Delamination Durability of Composite Materials for Rotorcrafts," NASA/Army Rotoreraft Technology. NASA CP2495. National Aeronautics and Space Administration. Washington. D.C. 1988. pp. 573-605

2. Mali, S Yun, K.T. and Kochnar. NK. "Characterization of Matrix Toughness Effects on Cyclic Growth in Graphite Fibre Composite Materials." Fatigue and Fracture. Cincinnati, OH, April 1987.

3. O'Brien, T.K., "Generic Aspects of Delamination in Fatigue of Composite Materials." Joumal of American Helicopter Society: Vol. 32. No. 1. January 1987. pp. 13-18.

4. Martin, R.H and Murri. G.B. "Characterization of Mode I and Mode II Delamination Growth and Thresholds in Graphite/PEEK Composites." NASA TM 100577. National Aeronautics and Space Administration. Washington, D.C., 1988

5. William, J.G., "Fracture Mechanics of Anisotropic Materials," Composite Muterial Serics Application of Fracture Mechanics to Composite Materials, Vol 6. Klaus Friedrich, Ed. 1989, pp. 3-38.

6. Jayant. M.M. and Donald. F.A.. "Energy Release Rate During Delamination Crack Growth in Notched Composite Laminates." Delamination and Debonding of Matcrials. ASTM STP 876, W.S. Johnson, Ed., 1985, pp. 100-101.

7. Davies. P. and Benzeggagh. M.L.. "Interlaminar Mode 1 Fracture Testing," Composite Material Series: Application of Fracture Mechanics to Composite Materials, Vol 6, Klaus Friedrich, 1989, pp. $81-112$.

8. Roderick. H. and Martin, G. B.M.. "Characterization of Mode 1 and Mode II Delamination Growth and Thresholds in AS4/PEEK Composites." Composite Materials: Testing and Design (ASTM STP. 1059), Garbo. Ed, cvol. 9. February 1990, pp. 252-256.

9. Chai, H.. "Bond Thickness Effect in Adhesive Joints and Its Significance for Mode I Interlaminar Fracture of Composites." Composite Materials: Testing and Design (ASTM STP 893) Seventh Con. ference, James W. Whitney. Ed., pp. 209-212.

10. "Standard Test Method for Mode I Interlaminar Fracture Toughness of Unidirectional Fibre Reinforced Polymer Matrix Composites." ASTM D5528-95a. American Society for Testing and Materials, May 1994.

11. O'Brien. T.K and Martin, R.H. "Results of ASTM Round Robin Testing for Mode I Interlaminar Fracture Toughness of Composite Materials." ASTM Journal of Composites Technology and Research, Vol. 15, No. 4, Winter 1993 (also in NASA TM 104222, 1992).

12. De Kalbermatten. T. Jaggi, R.. Fueler. P., Kausch. H.H. and Davies, P.. "Microfocus Radiography" Studies during Mode 1 Interlaminar Fracture Tests on Composites." Joutnal of Materials Science Letiers, Vol. 11, 1992, pp. 54.3-546.

13. Hashemi, S., Kinloch, A.J., and Williams. J.G., "Correction Needed in Double Cantilever Beam Tests for Assessing the Interlaminar Failure of Fibre Composites," Jounal of Matcrials Science Letrers. Vol. 8, 1989. pp. 125-129.

14. Berry, J.P., "Determination of Fracture Energies by the Cleavage Technique," Joumal of Applied Physics, Vol, 34, No. 1. January 1963, pp. 62-68

15. Kageyama. K. and Hojo. M.. "Proposed Method for Interlaminar Fracture Toughness Tests of Com. posite Laminates," Procedings of the Sth U.S./Japan Conference on Composite Materials. Tokyo. June 1990, pp. 227-234. 